\title{
Did Saving Mothers, Giving Life Expand Timely Access to Lifesaving Care in Uganda? A Spatial District-Level Analysis of Travel Time to Emergency Obstetric and Newborn Care
}

\author{
Michelle M. Schmitz, ${ }^{a}$ Florina Serbanescu, ${ }^{a}$ Vincent Kamara, ${ }^{b}$ Joan Marie Kraft, ${ }^{a}$ Marc Cunningham, ${ }^{c}$ \\ Gregory Opio, ${ }^{d}$ Patrick Komakech, ${ }^{e}$ Claudia Morrissey Conlon, ${ }^{c}$ Mary M. Goodwin, ${ }^{a}$ \\ on behalf of the Saving Mothers, Giving Life Working Group
}

A spatial analysis of facility accessibility, taking into account road networks and environmental constraints on travel, suggests that the Saving Mothers, Giving Life (SMGL) initiative increased access to emergency obstetric and neonatal care in SMGL-supported districts in Uganda. Spatial travel-time analyses can inform policy and program efforts targeting underserved populations in conjunction with the geographic distribution of maternity services.

\section{ABSTRACT}

Introduction: Interventions for the Saving Mothers, Giving Life (SMGL) initiative aimed to ensure all pregnant women in SMGL-supported districts have timely access to emergency obstetric and newborn care (EmONC). Spatial travel-time analyses provide a visualization of changes in timely access.

Methods: We compared travel-time estimates to EmONC health facilities in SMGL-supported districts in western Uganda in 2012, 2013, and 2016. To examine EmONC access, we analyzed a categorical variable of travel-time duration in 30-minute increments. Data sources included health facility assessments, geographic coordinates of EmONC facilities, geolocated population estimates of women of reproductive age (WRA), and other road network and geographic sources.

Results: The number of EmONC facilities almost tripled between 2012 and 2016, increasing geographic access to EmONC. Estimated travel time to EmONC facilities declined significantly during the 5-year period. The proportion of WRA able to access any EmONC and comprehensive EmONC (CEmONC) facility within 2 hours by motorcycle increased by $18 \%$ (from $61.3 \%$ to $72.1 \%, P<.01$ ) and $37 \%$ (from $51.1 \%$ to $69.8 \%, P<.01$ ), respectively from baseline to 2016. Similar increases occurred among WRA accessing EmONC and CEmONC respectively if 4 -wheeled vehicles (14\% and $31 \%$ increase, $P<.01$ ) could be used. Increases in timely access were also substantial for nonmotorized transportation such as walking and/or bicycling.

Conclusions: Largely due to the SMGL-supported expansion of EmONC capability, timely access to EmONC significantly improved. Our analysis developed a geographic outline of facility accessibility using multiple types of transportation. Spatial travel-time analyses, along with other EmONC indicators, can be used by planners and policy makers to estimate need and target underserved populations to achieve further gains in EmONC accessibility. In addition to increasing the number and geographic distribution of EmONC facilities, complementary efforts to make motorized transportation available are necessary to achieve meaningful increases in EmONC access.

\footnotetext{
a Division of Reproductive Health, U.S. Centers for Disease Control and Prevention, Atlanta, GA, USA.

b Baylor College of Medicine Children's Foundation-Uganda, Kampala, Uganda.

'Bureau for Global Health, U.S. Agency for International Development, Washington, DC, USA.

d Infectious Diseases Institute, Makerere University, Kibaale, Uganda.

${ }^{e}$ Division of Global HIV and TB, U.S. Centers for Disease Control and Prevention, Kampala, Uganda.

Correspondence to Florina Serbanescu (fxs7@cdc.gov).
}

\section{INTRODUCTION}

I

n 2015, an estimated 303,000 women around the world died of a maternal cause, and approximately 201,000 of these deaths occurred in sub-Saharan Africa. ${ }^{1}$ Additionally, almost half of the 2.6 million stillbirths and $30 \%$ of newborn deaths in sub-Saharan Africa were due to intrapartum causes. ${ }^{2,3}$ Most maternal and newborn deaths are preventable with adequate care at birth. ${ }^{4}$ In 2004, the World Health Organization (WHO) recommended skilled birth attendance at every 
birth and estimated that $50 \%$ to $70 \%$ of maternal deaths could be averted with timely access to emergency obstetric interventions. ${ }^{5,6}$ However, access to quality services in low-resource countries continues to be a challenge, especially for women and newborns who require emergency obstetric and newborn care (EmONC).

Physical distance to health care facilities has been widely recognized as an important determinant of accessing health facility delivery. ${ }^{7-10}$ While EmONC has been considered an essential strategy to save maternal and newborn lives, EmONC coverage in sub-Saharan Africa remains

GIS has expanded our ability to provide more accurate estimates of travel time to and disparities in access to EmONC. uneven and met need for EmONC has remained low. ${ }^{1-13}$ For example, in Mali, substantially higher maternal case-fatality rates were associated with travel times greater than 2 hours among women who accessed hospital care in 20052007. ${ }^{14}$ For women who need obstetric and other emergency surgery, the benchmark proposed by WHO is no more than 2 hours of travel time to the nearest facility with surgical capacity, which is roughly the interval from onset of bleeding to death if a woman with obstetric hemorrhage does not receive adequate treatment. ${ }^{15,16}$ Health researchers have suggested that at least $80 \%$ of any country's population should have access to selected emergency surgical and anesthesia services, including cesarean deliveries, within the 2-hour time frame. ${ }^{16,17}$

Adequate availability of EmONC services is defined by WHO as an area having at least 5 EmONC facilities, including at least 1 comprehensive EmONC (CEmONC) facility, per 500,000 population. ${ }^{15}$ Although the ratio of EmONC facilities to the population has been used as a proxy for adequate distance or travel time to reach a facility during an emergency, an optimal geographic distribution of EmONC services is also a critical determinant of timely access. ${ }^{15}$ To achieve the 2030 Sustainable Development Goal 3.1 of reducing global maternal mortality to less than 70 maternal deaths per 100,000 live births, ${ }^{18}$ researchers and policy makers have called specifically for the equitable distribution of EmONC facilities.

Implemented between 2012 and 2017, the Saving Mothers, Giving Life (SMGL) project aimed to rapidly reduce deaths related to pregnancy and childbirth through the implementation of multiple evidence-based approaches to address the 3 dangerous delays pregnant women face in childbirth: delays in deciding to seek care, delays in reaching a facility in time, and delays in receiving quality care at facilities. ${ }^{19-22}$ To reduce the second and third delays, the SMGL initiative sought to make facility delivery care accessible to all women within 2 hours. This goal required that SMGL-supported districts had a sufficient number of EmONC facilities equitably distributed geographically and adequate transportation to reach appropriate care. Consequently, SMGLsupported efforts in Uganda focused on improving availability and distribution of EmONC services, expanding motorized transportation to these facilities through vouchers for motorcycle taxis, and creating a coordinated ambulance service. $^{23-25}$

Improved spatial analyses using geographic information system (GIS) technology has expanded our ability to provide more accurate estimates of travel time to and disparities in access to EmONC. ${ }^{26,27}$ Travel-time modeling, estimating the most efficient travel time to a facility along established roads and walking paths, has emerged as one of the most robust analytical spatial techniques applied in maternal health. ${ }^{27}$ Rather than calculating unrealistic straight-line distances, these algorithms account for the effects of elevation, road conditions, and landscape barriers. Furthermore, these algorithms allow for the estimation of travel times using different transportation modes, such as on foot (walking), bicycle, motorcycle, or car/truck/ ambulance (4-wheeled vehicles) and corresponding travel speeds.

Because national government health planning is frequently organized and implemented at the district level, spatial analyses to support district and subdistrict interventions are greatly needed. Most studies of accessibility to EmONC care in sub-Saharan Africa, however, have focused on the national level. ${ }^{28-30}$ A few studies have analyzed point-in-time accessibility at subnational and administrative levels, mapped adverse maternal outcomes, prioritized ambulance services, or pinpointed underserved areas necessitating EmONC upgrades. ${ }^{30-32}$ This study adds to the literature by using travel-time accessibility modeling to assess changes in estimated travel time to EmONC in SMGL-supported districts in Uganda over the 5-year period of implementation. We examine whether geographic access improved during SMGL implementation and identify areas where access issues persisted at the conclusion of the project.

\section{METHODS}

The 4 SMGL-supported districts in UgandaKabarole, Kamwenge, Kibaale, and Kyenjojoform a contiguous unit in the western region of 
the country. Among the combined 2017 population of just over 2 million were an estimated 538,706 women of reproductive age (WRA) aged between 15 and 49 years (Table 1). ${ }^{19}$ Population density is low, with over $78 \%$ of the 4 -district area designated as rural and the largest urban population residing in Kabarole. ${ }^{34,35}$

Transportation challenges are common in the SMGL-supported districts. The topography is mountainous, particularly in Kibaale district. Large national parks are mostly impassable forest and rugged terrain, and numerous rivers and lakes create geographic barriers (Figure 1). Only a small portion of the rural road network is passable by 4 -wheeled vehicles, and only 2 paved roads connect Kamwenge and Kyenjojo districts with Fort Portal town, the district capital of Kabarole. Kibaale district did not have any paved roads during the SMGL implementation period.

The measurement of EmONC functionality used in our analysis was based on facility performance of a core set of lifesaving interventions, known as "signal functions," in the 3 months prior to the health facility assessments (HFAs). ${ }^{36}$ EmONC facilities are defined as having the ability to, at a minimum, (1) administer parenteral antibiotics, (2) administer uterotonic drugs for active management of the third stage of labor and prevention of postpartum hemorrhage, (3) use parenteral anticonvulsants for the management of pre-eclampsia/eclampsia, (4) perform manual removal of placenta, (5) perform removal of retained products, (6) perform assisted vaginal delivery, and (7) perform neonatal resuscitation. CEmONC facilities have the additional capability to perform cesarean deliveries and blood transfusion. ${ }^{15}$ Although the Ugandan Ministry of Health has further mandates about the distribution of government facilities, ${ }^{37}$ our analysis applies WHO benchmarks for EmONC and CEmONC of at least 5 EmONC facilities, including at least 1 CEmONC facility, per 500,000 population. SMGL-supported facilities include those added to the study area during the SMGL initiative as well as existing facilities that were upgraded to provide EmONC.

\section{Data Sources}

The initiative employed HFAs and other monitoring and evaluation methods to assess the progress and impact of interventions across the SMGL's implementation phases: Phase 0 (pre-implementation planning in 2011-2012), Phase 1 (June 2012 to December 2013), and Phase 2 (January 2014 to October 2017).

\section{Health Facility Assessments}

To assess changes in facility infrastructure, functionality, and use, SMGL implementing partners in Uganda conducted HFAs in SMGL-supported districts at baseline, the end of Phase 1, and endline (November 2016). ${ }^{19}$ The 3 assessment periods were conducted in 111,127 , and 129 health facilities, respectively, which provided over $95 \%$ of all facility deliveries in the SMGL study area at each time point. HFAs documented performance of EmONC functions during the 3 months prior to the assessments as well as the geographic location of facilities (accuracy of \pm 10 meters). ${ }^{37}$ Our analyses used all facilities included in HFAs for any of the 3 assessment periods.

\section{Geographic Data}

We used land cover data obtained from the Regional Centre for Mapping of Resources for Development, ${ }^{33}$ initially collected with a 30-by-30 meter resolution and subsequently aggregated within AccessMod version 5, revision
EmONC

functionality was based on facility performance of a core set of lifesaving interventions, known as "signal functions."

\section{SMGL-supported health facilities provided care for over $95 \%$ of all facility deliveries in the SMGL study area at each time point.}

TABLE 1. Demographic Factors, SMGL-Supported Districts in Uganda, 2016

\begin{tabular}{lcccr}
\hline District & Total Population, 2016 & Number of WRA, 2016 & Population Density $\left(\text { People/km }{ }^{\mathbf{a}}\right)^{\mathbf{b}}$ & Urbanization Level (\% Urban) $^{\mathbf{b}}$ \\
\hline Kabarole & 456,052 & 121,794 & 259 & 26.0 \\
\hline Kamwenge & 392,501 & 101,650 & 177 & 5.5 \\
\hline Kibaale & 818,176 & 206,596 & 185 & 7.9 \\
\hline Kyenjojo & 428,451 & 108,666 & 179 & 15.4 \\
\hline Total & $2,095,180$ & 538,706 & 173 & 21.3 \\
\hline
\end{tabular}

Abbreviations: km², kilometers squared; SMGL, Saving Mothers, Giving Life; WRA, women of reproductive age.

a Estimated from SMGL Reproductive Age Mortality Study, 2017.19

b 2014 National Census Main Report, Uganda Bureau of Statistics. ${ }^{33}$ 
FIGURE 1. Visual Representation of Data Sources Used in Health Care Accessibility Modeling Analysis

\section{Digital Elevation Model}

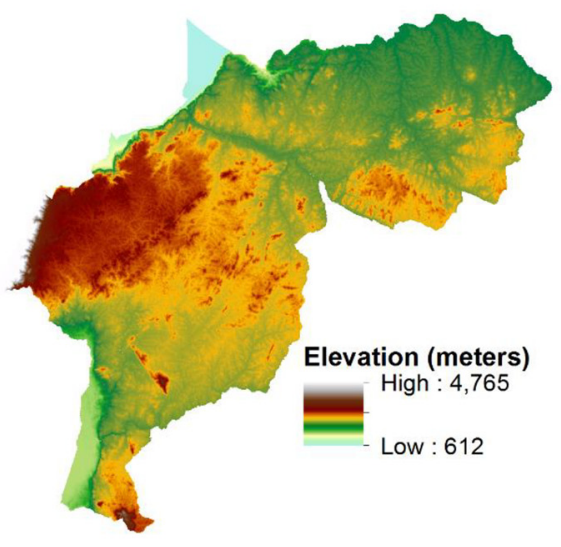

\section{Land Cover, Rivers,} and Water Bodies

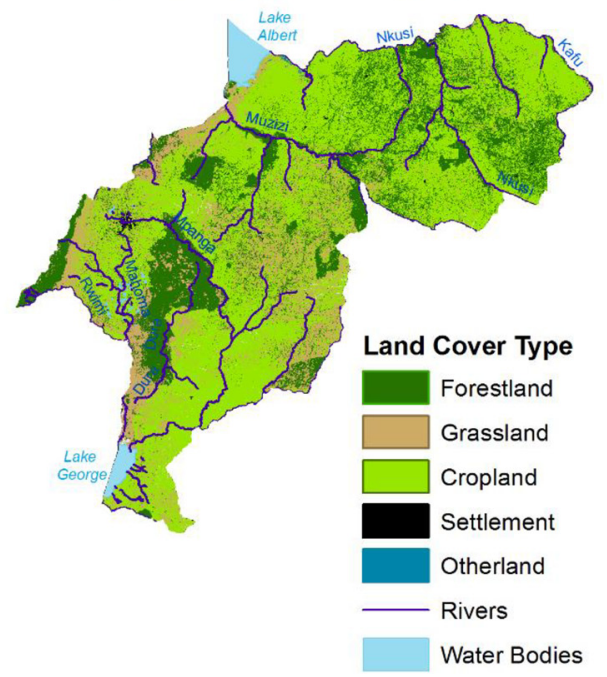

Population and National Parks
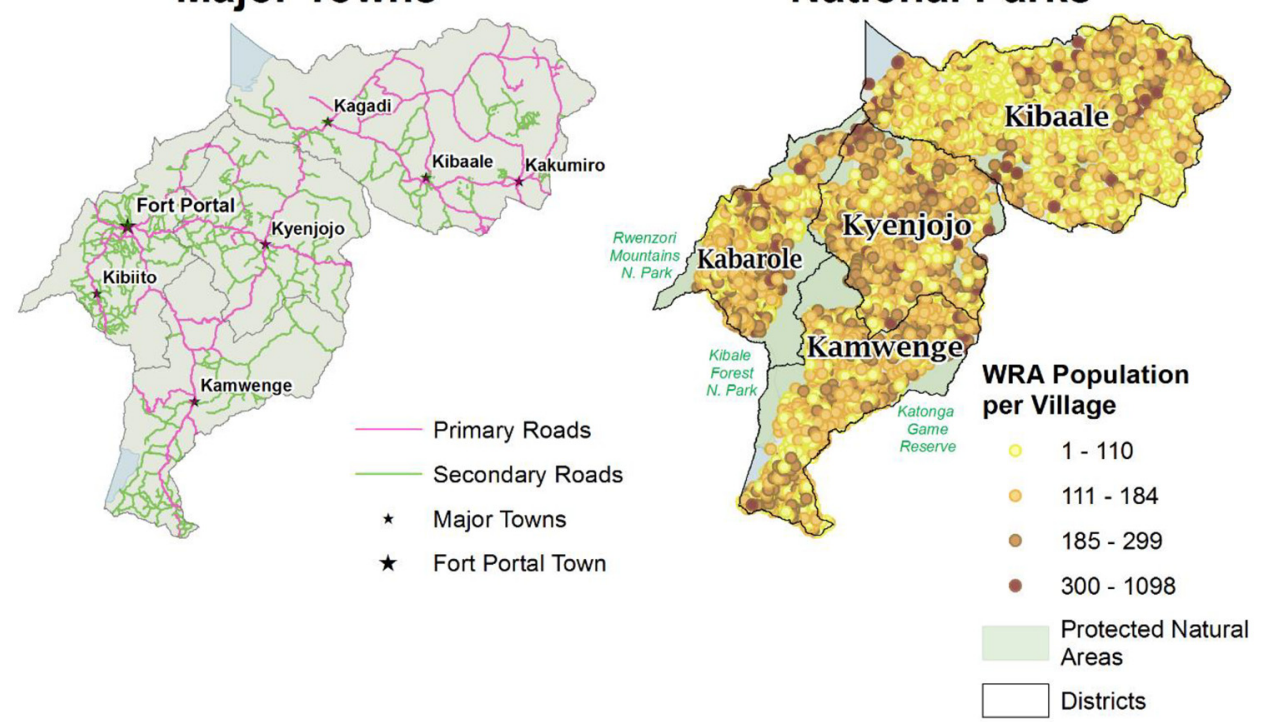

5.1.18 (WHO, Geneva, Switzerland,) to a 92-by92 meter resolution to match the resolution of other layers (Figure 1). This land cover raster used a 6-ecosystem scheme that accounted for forestland, grassland, cropland, settlement, wetlands, and other land cover.
We created updated shapefiles for lakes and rivers using Uganda Bureau of Statistics (UBOS) data ${ }^{35}$ and OpenStreetMap (www.openstreetmap.org) shapefiles. When a data source had incomplete information about a river network, we manually digitized our master river shapefile with Digital 
Globe EnhancedView Web Hosting Service (https://evwhs.digitalglobe.com/myDigitalGlobe) satellite imagery obtained in June 2018. We considered water bodies as being completely impassable and rivers as being partially passable, if crossed by a primary or secondary road, by an assumed bridge.

We merged and cleaned the shapefiles of the UBOS road network data from the 2014 Uganda Census and the OpenStreetMap road network digitized in mid-December 2017 via the Humanitarian OpenStreetMap Team. ${ }^{38,39}$ We created subsets of all primary (between district capitals) and secondary road shapefiles (between towns and major villages) for use in the AccessMod analysis (Figure 1). The resulting road shapefile was cross-checked against Digital Globe satellite imagery. We ascertained the proportion of roads that were paved and unpaved and changes in paving that occurred over time. Since the majority of the roads were unpaved and no substantive changes occurred within the project duration, we applied travel speeds for unpaved roads only to yield the most conservative travel time estimates.

Elevation and slope data were obtained from the Shuttle Radar Topography Mission digital elevation model produced by the U.S. Geological Survey, both with a 92-by-92 meter pixel resolution. ${ }^{40}$ The model provided elevation information to the tool and was used to determine the relative slope of each raster pixel.

National parks, from the World Database on Protected Areas, were derived by the United Nations Environment World Conservation Monitoring Centre and considered impassable unless a road passed through it. They were included in the final maps to provide context. ${ }^{41}$

Within AccessMod, the land cover, road network, river, and water body datasets were combined into a merged land cover raster file, with a 92-by-92 meter resolution, and used in the travel-time analyses.

\section{Population Data}

Household population data from all villages in the 4 Ugandan districts were collected in 2017 as a component of the SMGL Reproductive Age Mortality Study (RAMOS). ${ }^{19}$ While RAMOS's primary aim was to measure and identify main causes of maternal mortality, the study also enumerated households, household members, WRA, and all recent deaths. ${ }^{19}$ We crosschecked geographic coordinates collected in the
2017 RAMOS with UBOS geographic data and reconciled discordant coordinates. ${ }^{34,35,42}$ Overall, 538,706 WRA resided in 3,749 villages across the 4 districts in 2016 (Figure 1).

\section{Analytic Methods}

To assess whether districts met the WHO benchmark of EmONC availability, we followed the WHO guidelines, which recommend a minimum of 5 EmONC facilities per 500,000 population, including at least 1 CEmONC facility in each district. ${ }^{37}$ For each district, we calculated the recommended number of EmONC facilities by dividing the estimated district population by 100,000. For each time period, we then computed the observed number of EmONC facilities and compared them to the recommended number of facilities.

We estimated the minimum travel time to the nearest EmONC and CEmONC facilities using the AccessMod Accessibility module. AccessMod uses the least-cost path algorithm to calculate the quickest way of traveling between 2 points, using roads or off-road travel, as appropriate. ${ }^{43}$ Travel time is also dependent on travel speeds for each transportation mode-walking, bicycles, motorcycles, and 4-wheeled vehicles-with land cover influencing the speed of walking. Bicycles and motorcycles can be outfitted with sidecars as makeshift ambulances. ${ }^{43,44}$ We determined these speeds using direct observation combined with other published sources. ${ }^{34,43,46-51}$ Walking was the only mode of travel used for areas without primary or secondary roads. Speeds were reduced by two-thirds to account for slower transportation speeds of pregnant women and to further account for travel on unpaved roads. Tobler's function, which corrects walking speed based on the direction of slopes on the terrain derived from the digital elevation model, was used to adjust both walking and bicycling speeds. ${ }^{52}$

We performed AccessMod travel-time simulations for the 4 transportation modes to EmONC and CEmONC facilities, focusing on a 2-hour upper limit of the estimated travel time, consistent with WHO recommendations for EmONC access. ${ }^{15}$ All estimated transportation modes, except walking, assumed access to the nearest road by foot and travel by an immediately available vehicle to the closest facility providing EmONC care. We did not consider district boundaries as barriers to movement; however, we only estimated access to EmONC facilities within the SMGL-supported districts, allowing for movement between districts but not to facilities outside these districts. With

\section{AccessMod uses the least-cost path algorithm to calculate the quickest way of traveling between 2 points, using roads or off-road travel, as appropriate.}




At baseline,
substantial
differences were
noted between the
recommended
and observed
number of EmONC
facilities in the
SMGL-supported
districts.

ArcGIS Desktop version 10.3.1 (Environmental Systems Research Institute, Redlands, CA), we created a continuous distribution of estimated travel time needed to reach an EmONC facility for each transportation mode and categorized the continuous travel-time raster into 4 incremental 30minute travel-time zones (0 to 30 minutes, 31 to 60 minutes, 61 to 90 minutes, and 91 to $120 \mathrm{~min}$ utes), plus a fifth category for more than 2 hours of travel time (>120 minutes). Instead of using AccessMod's native Zonal Statistics module, we converted the raster into a shapefile of different travel-time zones in ArcGIS version 10.5. We mapped all travel-time zones to reach any EmONC and CEmONC services for each transportation mode.

Combining the travel-time zones with georeferenced village population data, we estimated the number and proportion of WRA with access to EmONC and CEmONC services within each travel-time zone. We obtained the proportion of

At endline,
Kyenjojo and
Kabarole
exceeded the
WHO-
recommended
number of EmONC
facilities,
achieving 8
EmONC facilities
for over 400,000
people per district.
WRA within a travel-time zone by summing all WRA residing in villages located within each travel-time zone then dividing by the complete enumerated WRA population. We defined "adequate EmONC access" as the ability to reach an EmONC facility within 2 hours of travel time, and "poor EmONC access" as the inability to reach an EmONC facility within 2 hours. We assumed all travel to be from a woman's home to a facility.

We calculated the relative percentage change in the proportions of WRA residing within each travel-time zone and across each transportation mode, by subtracting the baseline percentage from the endline percentage and dividing by the baseline percentage. For the population percentages, $z$ scores, based on the normal approximation to the binomial distribution, were used to calculate $P$ values.

\section{Ethical Approval}

The study protocol was reviewed and approved by recognized ethics committees in Uganda and complied with Ugandan Ministry of Health procedures for protecting human subjects. This study was reviewed and approved by the U.S. Centers for Disease Control and Prevention's Center for Global Health Human Subject Review Board, which determined that it did not constitute human subjects research.

\section{RESULTS}

At SMGL baseline, substantial differences were noted between the recommended and observed number of EmONC facilities in the 4 SMGLsupported districts (Table 2). Only 10 facilities in a population of over 2 million provided EmONC services, 7 of which provided CEmONC. None of the districts met the recommended benchmark for per-capita EmONC availability. Three districts met the recommended benchmark of at least 1 CEmONC facility at baseline (Kabarole, Kibaale, and Kyenjojo), while Kamwenge had no CEmONC facility.

SMGL increased the number of facilities performing EmONC across all districts. Most of the increases occurred during SMGL's first year (Phase 1), when the total number of EmONC facilities more than doubled, from 10 to 25 facilities (Table 2). Comparatively fewer changes in the number of EmONC facilities occurred between the conclusion of Phase 1 and endline; an additional 2 EmONC facilities in Kibaale and 1 in Kyenjojo were added, while Kamwenge lost 2 EmONC facilities.

At endline, Kyenjojo and Kabarole exceeded the WHO-recommended number of EmONC facilities, achieving 8 EmONC facilities for over 400,000 people per district. Although Kamwenge attained the WHO benchmarks in Phase 1, it lacked the recommended per-capita number of EmONC facilities at endline. Kibaale, the most populous district, never met the WHO benchmarks for EmONC, despite increasing its total number of EmONC facilities from 5 to 7, with 5 of the 7 providing $\mathrm{CEmONC}$ at the conclusion of both Phase 1 and endline.

Table 3 provides the percentage of estimated WRA population able to reach EmONC and CEmONC within 2 hours or more than 2 hours, by transportation mode, for the 4 districts combined. The greater number of EmONC facilities resulted in significant increases in the proportion of WRA with "adequate" access (within 2 hours) to both EmONC and CEmONC (Table 3).

As expected, there were large differences in access between nonmotorized and motorized transportation modes. However, adequate access improved substantially during the SMGL initiative, regardless of the transportation mode. Adequate access to EmONC services by nonmotorized transportation (walking) increased from $6.7 \%$ at baseline to $15.0 \%$ at endline $(125 \%$ relative increase) and from $17.9 \%$ to $37.6 \%$ by bicycle (110\% increase). Adequate EmONC access by motorized transport was higher; access to EmONC by motorcycle increased from $61.3 \%$ at baseline to $72.1 \%$ at endline (17\% increase), while access by 4 -wheeled vehicle rose from 
TABLE 2. Recommended and Observed Number of EmONC and CEmONC Facilities per Capita in SMGL-Supported Districts at Baseline (2012), Phase 1 (2013), and Endline (2016)

\begin{tabular}{|c|c|c|c|c|c|c|c|c|c|c|c|c|}
\hline & \multicolumn{4}{|c|}{ Baseline } & \multicolumn{4}{|c|}{ Phase 1} & \multicolumn{4}{|c|}{ Endline } \\
\hline & Population $^{a}$ & $\begin{array}{l}\text { Recommended } \\
\text { EmONC }^{\mathrm{b}, \mathrm{c}}\end{array}$ & $\begin{array}{l}\text { Observed } \\
\text { EmONC }^{, d d}\end{array}$ & $\begin{array}{l}\text { Observed } \\
\text { CEmONC, }\end{array}$ & Population $^{a}$ & $\begin{array}{l}\text { Recommended } \\
\text { EmONC }^{\mathrm{b}, \mathrm{c}}\end{array}$ & $\begin{array}{l}\text { Observed } \\
\text { EmONC }\end{array}$ & $\begin{array}{l}\text { Observed } \\
\text { CEmONC }\end{array}$ & Population ${ }^{f}$ & $\begin{array}{c}\text { Recommended } \\
\text { EmONC }^{\mathrm{b}, \mathrm{c}}\end{array}$ & $\begin{array}{l}\text { Observed } \\
\text { EmONC }^{d}\end{array}$ & $\begin{array}{l}\text { Observed } \\
\text { CEmONC, }\end{array}$ \\
\hline Kabarole & 415,600 & 5 & 3 & 3 & 421,700 & 5 & 8 & 6 & 456,052 & 5 & 8 & 6 \\
\hline Kibaale & 681,300 & 7 & 3 & 3 & 717,500 & 8 & 5 & 5 & 818,176 & 9 & 7 & 5 \\
\hline Kyenjojo & 383,600 & 4 & 1 & 1 & 397,700 & 4 & 7 & 3 & 428,451 & 5 & 8 & 3 \\
\hline Total & $1,812,500$ & 20 & 10 & 7 & $1,876,400$ & 21 & 25 & 16 & $2,095,180$ & 23 & 26 & 17 \\
\hline
\end{tabular}

Abbreviations: CEmONC, comprehensive emergency obstetric and neonatal care; EmONC, emergency obstetric and neonatal care; RAMOS, Reproductive Age Mortality Study; SMGL, Saving Mothers, Giving Life; WHO, World Health Organization.

a Estimated from SMGL RAMOS $2013 .^{19}$

${ }^{b}$ EmONC encompasses facilities performing at least 7 lifesaving interventions within the past 3 months. CEmONC indicates those facilities providing 9 lifesaving interventions in the past 3 months.

${ }^{c}$ Uses the WHO minimum-recommended number of EmONC and CEmONC per 500,000 population (5 EmONC, including at least $1 \mathrm{CEmONC}$, per 500,000$)$. 'Observed EmONC includes facilities that may not have provided assisted vaginal delivery in the past 3 months.

e Observed CEmONC includes facilities that may not have provided assisted vaginal delivery in the past 3 months; a few facilities reported shortage of blood in Phase 1 in the previous 3 months but were still classified as CEmONC facilities.

${ }^{f}$ Estimated from SMGL RAMOS 2017. ${ }^{19}$

Source: SMGL Uganda Health Facility Assessments, 2012, 2013, and 2016

$65.1 \%$ to $74.1 \% \quad(14 \%$ increase). Relative increases in the percentage of WRA with adequate access to CEmONC using motorized transport also occurred. Adequate access to CEmONC by motorcycle increased from $51.1 \%$ to $69.8 \%(37 \%$ increase), while access by 4 -wheeled vehicles increased from $55.2 \%$ to $72.3 \%$ of WRA $(31 \%$ increase). Additionally, the percentage of WRA with access to EmONC within 60 minutes or less by motorcycle increased from $27.3 \%$ to $44.4 \%$ (63\% increase) and by 4 -wheeled vehicles increased from $33.1 \%$ to $48.6 \%$ (47\% increase).

When stratified by district, there were substantial differences in the baseline and endline proportions of WRA with adequate access to CEmONC (Figure 2), with similar patterns for EmONC access by district (data not shown). Kabarole, the most urbanized and densely populated district, began SMGL with $89.6 \%$ of estimated WRA having adequate access to CEmONC, which increased to $93.1 \%$ at endline, a relative increase of about $3 \%$. Conversely, in sparsely populated Kamwenge, where only $13.1 \%$ of estimated WRA had adequate access at baseline, the added SMGL-supported facilities increased adequate CEmONC access to $71.6 \%$ at endline, a $447 \%$ increase. In Kibaale, the proportion of WRA with adequate access to CEmONC was $41.8 \%$ at baseline but increased to
$56.5 \%$ by endline, a $35 \%$ increase. In Kyenjojo, adequate CEmONC access increased from $66.9 \%$ of WRA at baseline to $70.5 \%$ at endline, a relatively modest $5 \%$ increase.

Maps depicting travel-time zone access to EmONC and CEmONC by nonmotorized (Figure 3 and Figure 4) and motorized (Figure 5 and Figure 6) transportation help visualize access improvements that occurred after the addition of new services supported by SMGL. The maps provide a gradient of the travel time needed for adequate access to EmONC services. Adequate access to EmONC facilities is shown in a greento-brown gradient, displaying 0 to 30 and 90 to 120 minutes, respectively. Areas outside of this gradient-whether gray, blue, or greendenote poor EmONC access.

At baseline, access to EmONC services was concentrated around major towns in Kabarole, Kyenjojo, and Kibaale, with some additional services along the Kabarole-Kamwenge road (Figure 3 and Figure 5). With the addition of new EmONC services through the SMGL initiative, areas with adequate access appear dispersed across the districts. For nonmotorized transportation, the amount of land covered by the zones of adequate access is small, indicating that the majority of WRA still had poor access in the absence of
In Kamwenge, where only $13.1 \%$ of WRA had adequate access at baseline, the added SMGLsupported facilities increased adequate CEmONC access to $71.6 \%$ at endline, a $447 \%$ increase. 
TABLE 3. Estimated Proportion of WRA Within Each Travel-Time Zone in SMGL-Supported Districts in Uganda (2012-2016), by Transportation Mode

\section{EmONC Facilities}

\begin{tabular}{lcccc}
\hline Baseline, & Phase 1, & Endline, & $\%$ & $\begin{array}{c}\text { Sig. } \\
2012(\%)\end{array}$ \\
$2013(\%)$ & $2016(\%)$ & Change $^{b}$ & Level $^{c}$
\end{tabular}

\section{CEmONC Facilities}

\begin{tabular}{lcccc}
\hline Baseline, & Phase 1, & Endline, & $\%$ & $\begin{array}{c}\text { Sig. } \\
2012(\%)\end{array}$ \\
$2013(\%)$ & $2016(\%)$ & Change $^{b}$ & Level $^{c}$
\end{tabular}

Transportation Mode ${ }^{a}$

Walking, minutes

\begin{tabular}{lrrrrrrrrrrrrr}
\hline $0-30$ & 1.4 & 2.4 & 2.6 & +88 & $* * *$ & 1.2 & 1.9 & 1.9 & +55 & $* * *$ \\
\hline $31-60$ & 1.5 & 3.5 & 3.5 & +131 & $* * *$ & 1.4 & 2.4 & 2.7 & +96 & $* * *$ \\
\hline $61-90$ & 2.0 & 4.0 & 4.4 & +124 & $* * *$ & 1.7 & 3.0 & 3.1 & +89 & $* * *$ \\
\hline $91-120$ & 1.8 & 4.3 & 4.5 & +152 & $* * *$ & 1.5 & 3.2 & 3.3 & +118 & $* * *$ \\
\hline$\leq 120$ & 6.7 & 14.2 & 15.0 & +125 & $* * *$ & 5.8 & 10.5 & 11.1 & +91 & $* * *$ \\
\hline$>120$ & 93.3 & 85.8 & 85.0 & -9 & $* * *$ & 94.2 & 89.5 & 88.9 & -6 & $* * *$
\end{tabular}

\section{Bicycle, minutes}

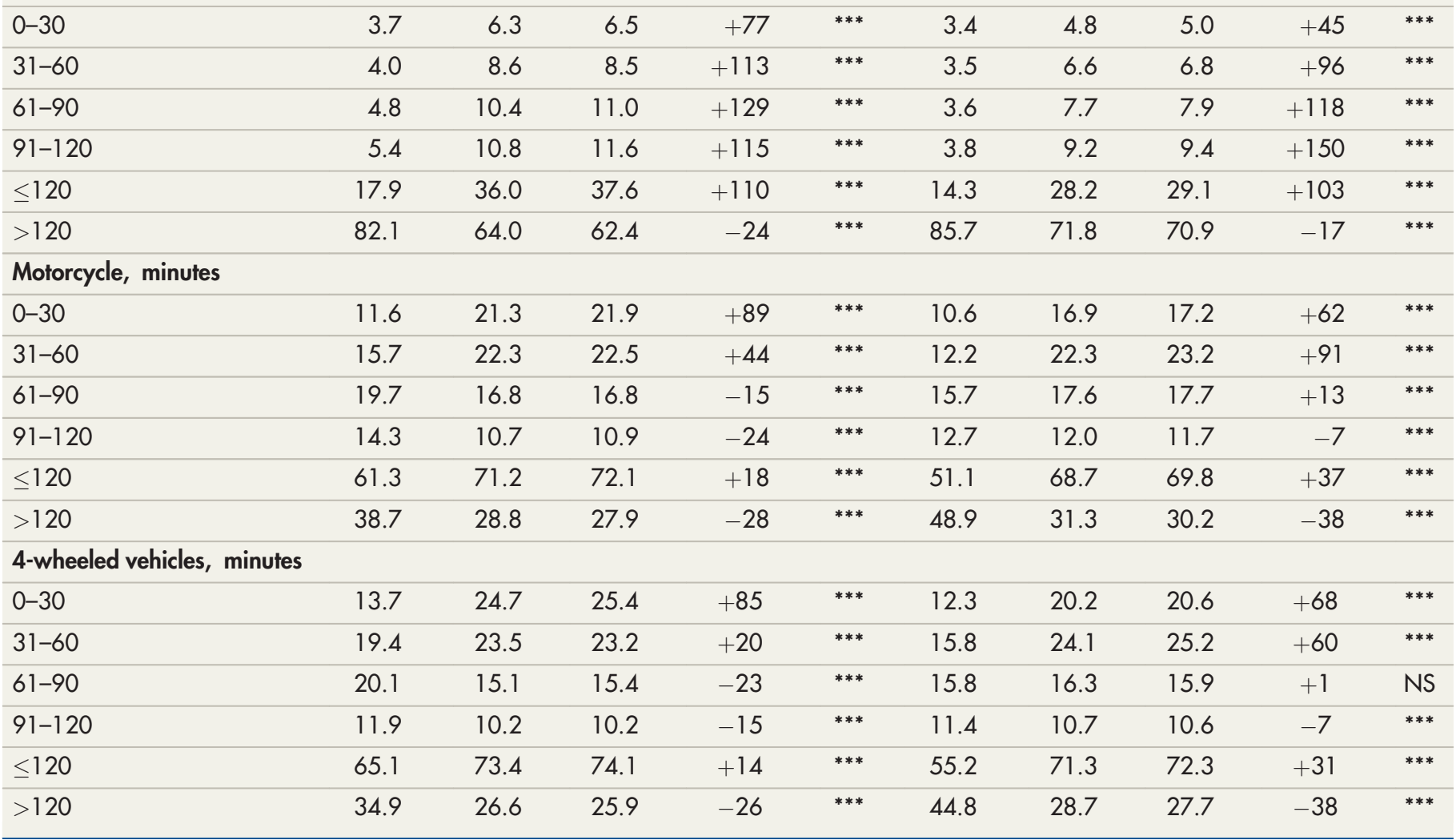

Abbreviations: CEmONC, comprehensive emergency obstetric and newborn care; EmONC, emergency obstetric and newborn care; SMGL, Saving Mothers, Giving Life; Sig. level, Significance level; WRA, women of reproductive age.

a Walking mode includes walking alone. Bicycle mode includes walking to a road and use of a bicycle. Motorized transportation modes (motorcycle, 4-wheeled vehicles) include walking to the road and use of a motorized transportation thereafter.

${ }^{b}$ Relative \% change (\% change) is calculated by the formula, $\left.(\mid p 2-p 1) / p 1\right) * 100$.

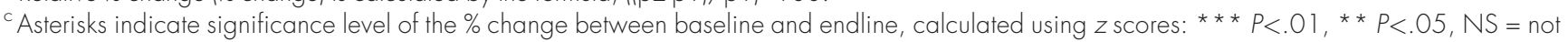
significant. 
FIGURE 2. Percentage of Women of Reproductive Age Living Within 2 Hours of CEmONC Facilities by Motorized Transportation and SMGL District

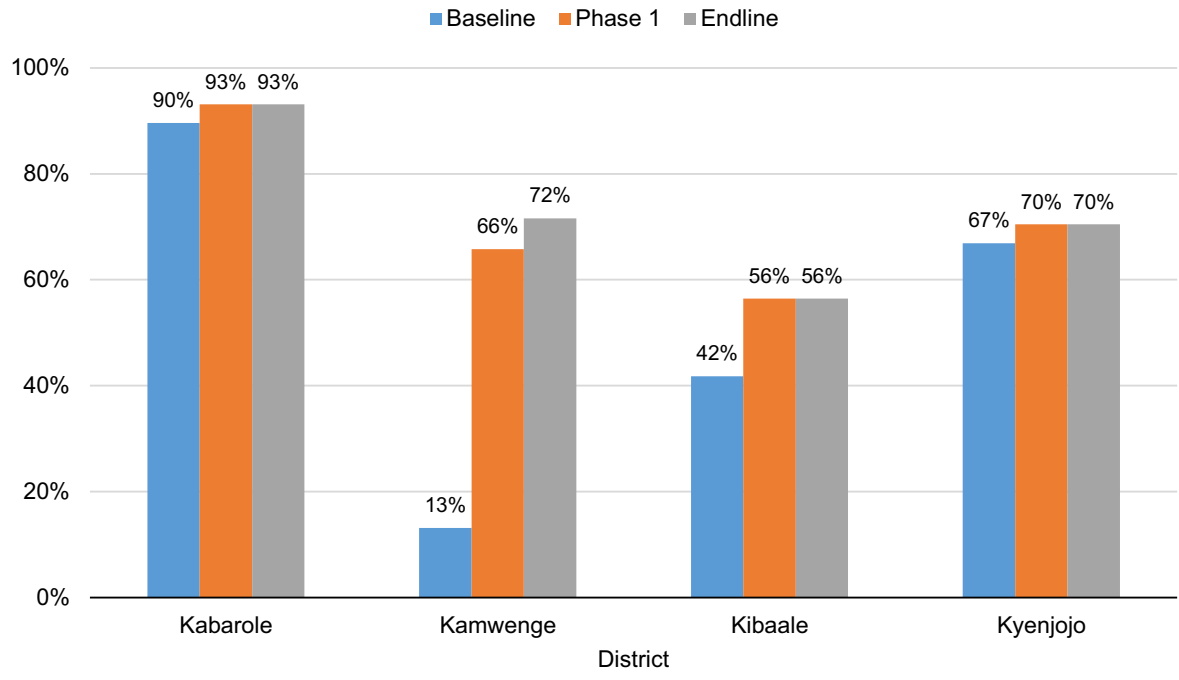

Abbreviations: CEmONC, comprehensive emergency obstetric and newborn care; SMGL, Saving Mothers, Giving Life.

motorized transport. Adequate access to EmONC by motorized transportation was clearly expanded into new areas of Kamwenge district and central and southern Kibaale districts. Similar geographic patterns were found for CEmONC access (Figure 4 and Figure 6). SMGL upgrades and additions led to more widespread distribution of adequate EmONC and CEmONC access. While the areas with poor EmONC and CEmONC access shrank in most districts, several notable gaps in access by motorized transportation remained, particularly on the northern border of Kibaale, in eastern Kamwenge, in western Kabarole, and on the border between Kabarole and Kamwenge.

\section{DISCUSSION}

Addressing access to care requires a systems approach, including synergistic interventions at the community, facility, and health system levels designed to decrease travel time to care and increase access to motorized transportation. Our travel-time analyses show that the SMGL initiative reduced travel time to EmONC services through a rapid expansion of health facilities able to provide EmONC. The number of facilities providing EmONC and CEmONC services more than doubled from baseline to endline. Two districts met the WHO standard for EmONC, while all 4 districts met the standard of at least 1 CEmONC facility. Overcoverage of EmONC care in Kabarole district and undercoverage in Kamwenge and Kibaale districts left the population of Kibaale and Kamwenge districts with less than the recommended number of EmONC facilities per capita by endline.

A central goal of the SMGL initiative was to ensure that all WRA in each SMGL-supported district had access to EmONC within 2 hours of travel. Despite SMGL's extensive facility upgrade achievements, an estimated one-quarter of WRA continued to have poor access to EmONC care by motorized transportation at the conclusion of the initiative. Because higher-level CEmONC facilities were distributed inequitably due to overconcentration in urban areas, access to CEmONC remained especially uneven across the districts. For example, despite Kyenjojo adding 2 facilities over the course of the SMGL initiative, the new CEmONC facilities were located close to an existing CEmONC facility. This led to only a $5 \%$ increase in adequate CEmONC access across the district by motorized transport. In contrast, in Kamwenge district, where access to CEmONC care by motorized transport at baseline was very limited, the addition of 3 geographically distributed CEmONC facilities significantly increased access to CEmONC care (447\% increase). Clustering of high-level facilities in urban areas is a problem for increasing access to care to larger geographic

\section{The number of facilities providing EmONC and CEmONC services more than doubled from baseline to endline.}


FIGURE 3. Distribution of Estimated Travel Time to EmONC Facilities, Walking or Bicycling and Walking

Strategic placement and equitable distribution of EmONC facilities in the remaining underserved areas could provide a far greater percentage of WRA with adequate access to EmONC care.
Walking, Baseline

Bicycling, Baseline
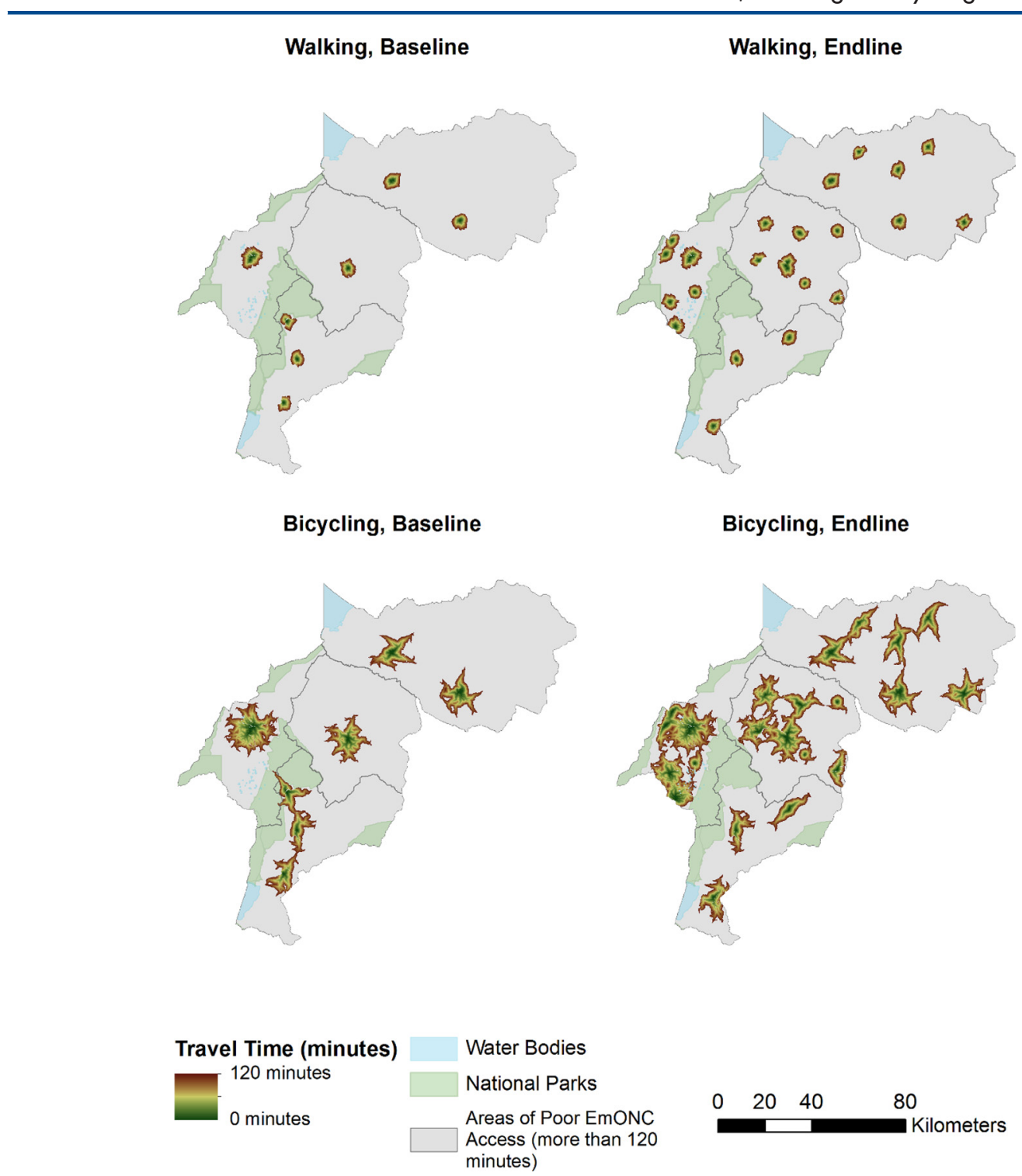

Bicycling, Endline

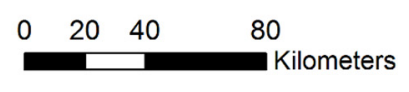

Abbreviation: EmONC, emergency obstetric and newborn care.

areas, unless access to motorized transport is increased.

It is worth noting that our analysis focused only on facilities that could provide the full complement of EmONC signal functions. Numerous facilities in SMGL-supported districts provided partial EmONC, with 4 to 5 signal functions, which did not meet the criteria for full EmONC functionality. Taking all facilities that provide delivery services into account, we found that $18 \%$ of WRA had poor motorized access-outside of 2 hours-to any facility that provided deliveries at endline (data not shown). To meet remaining geographic gaps, a combination of efforts to bring partial EmONC facilities to full EmONC capacity, combined with efforts to improve motorized transport access in these stillunderserved areas, could increase adequate access for WRA who still had poor access at the conclusion of SMGL. Strategic placement of EmONC facilities in the remaining underserved areas and a focus on equitable distribution could 
FIGURE 4. Distribution of Estimated Travel Time to CEmONC Facilities, Walking or Bicycling and Walking

Walking, Baseline

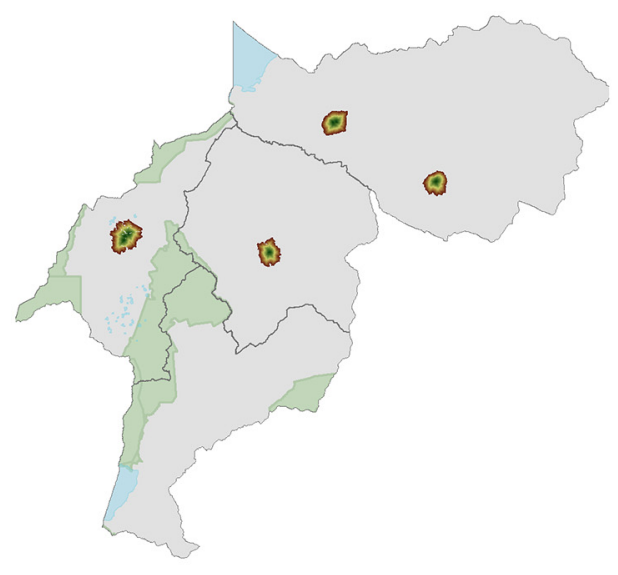

Bicycling, Baseline

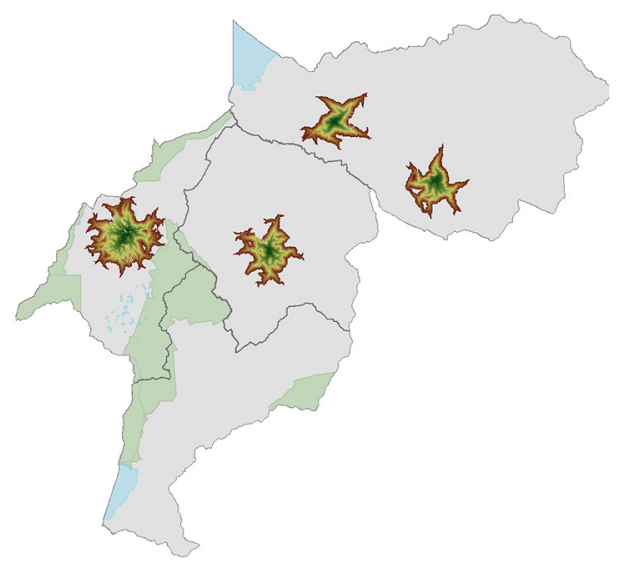

Walking, Endline

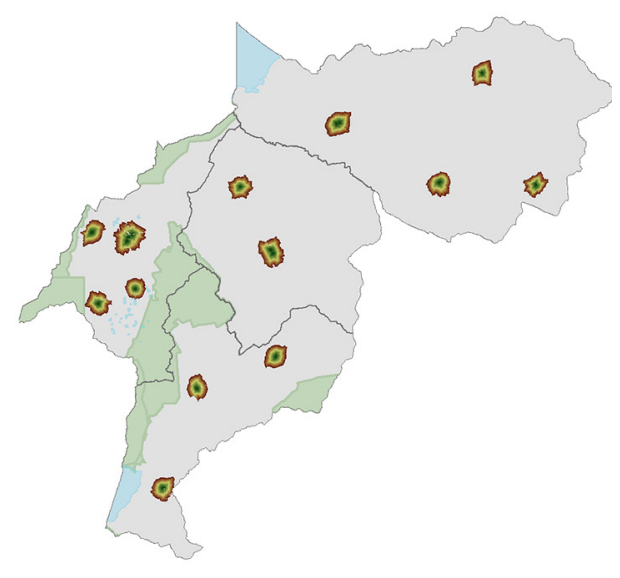

Bicycling, Endline

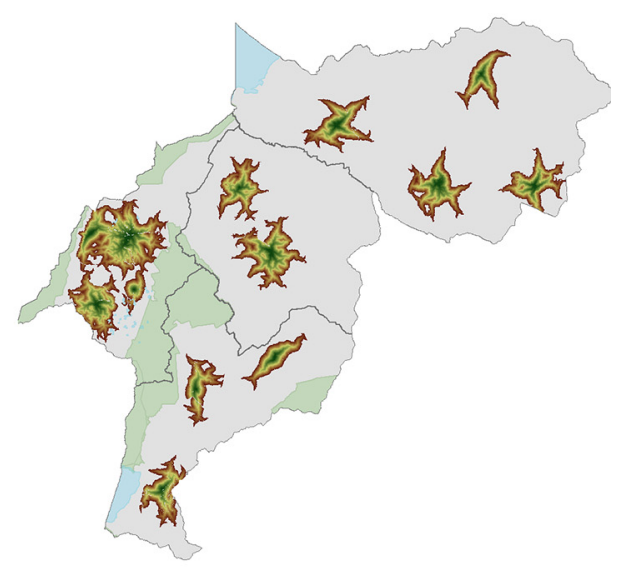

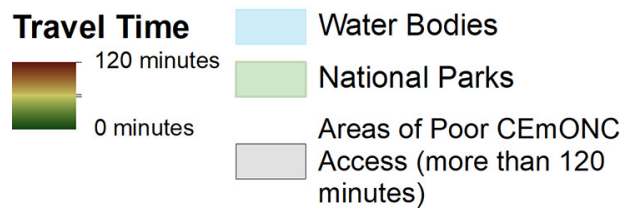

$0 \quad 20 \quad 40 \quad 80$

Kilometers

Abbreviation: CEmONC, comprehensive emergency obstetric and newborn care.

provide a far greater percentage of WRA with adequate access to EmONC care. The results of this analysis provide a geographic outline for future strategically located upgrades to facilities in areas with continued poor access. ${ }^{26,27}$ Additionally, the SMGL geodatabase could be used to inform other public health efforts in the districts, including immunization campaigns, 
FIGURE 5. Distribution of Estimated Travel Time to EmONC Facilities Using Motorized Transportation ${ }^{a}$

\section{Motorized Transportation, Baseline}

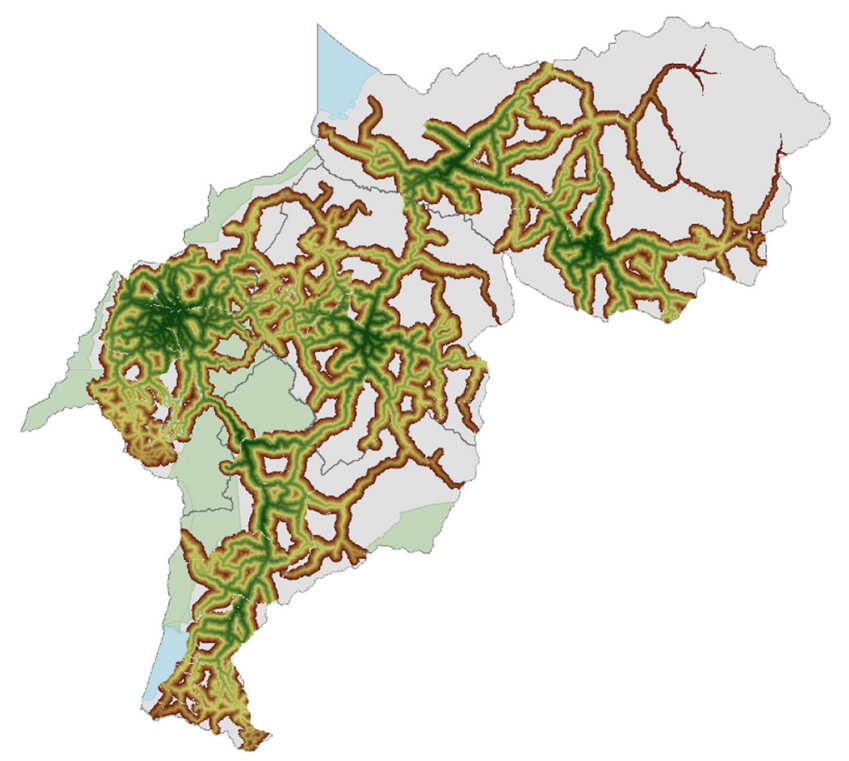

\section{Motorized Transportation, Endline}
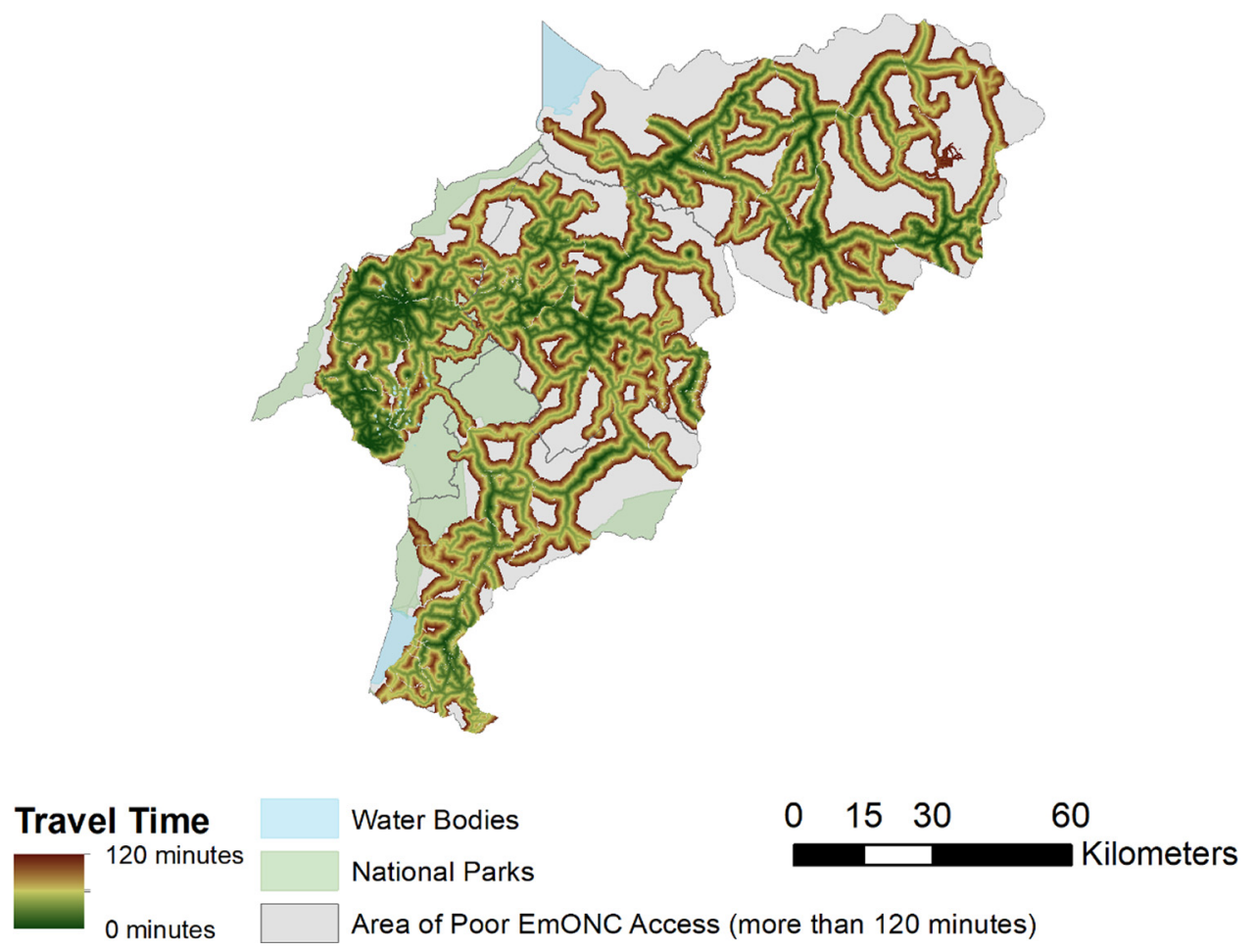

a Transportation defined as motorcycles or 4-wheeled vehicles.

Abbreviation: EmONC, emergency obstetric and newborn care. 
FIGURE 6. Distribution of Estimated Travel Time to CEmONC Facilities Using Motorized Transportation ${ }^{a}$

\section{Motorized Transportation, Baseline}

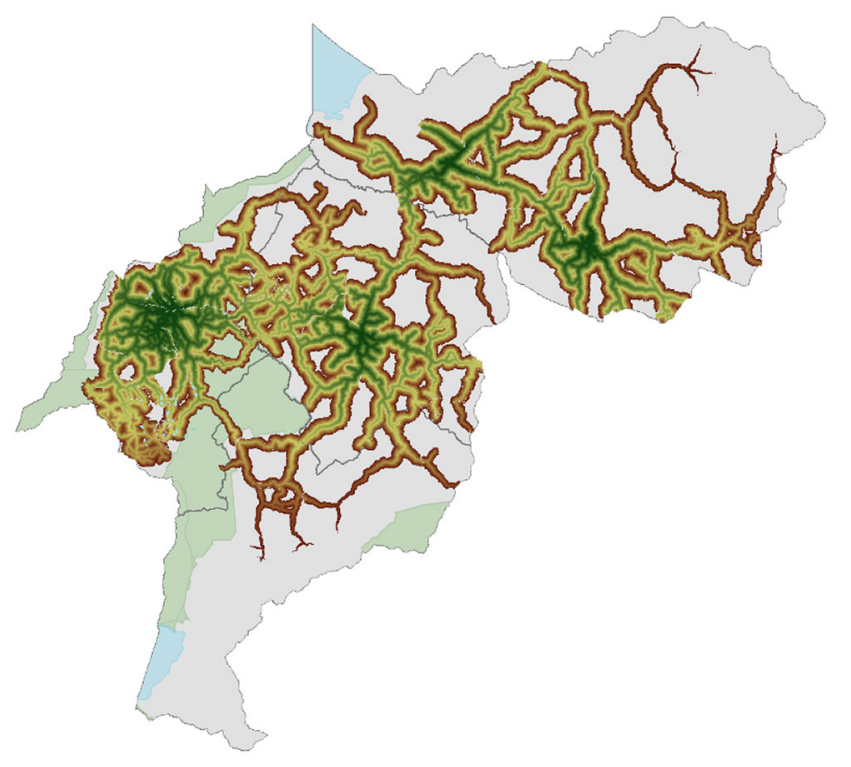

\section{Motorized Transportation, Endline}
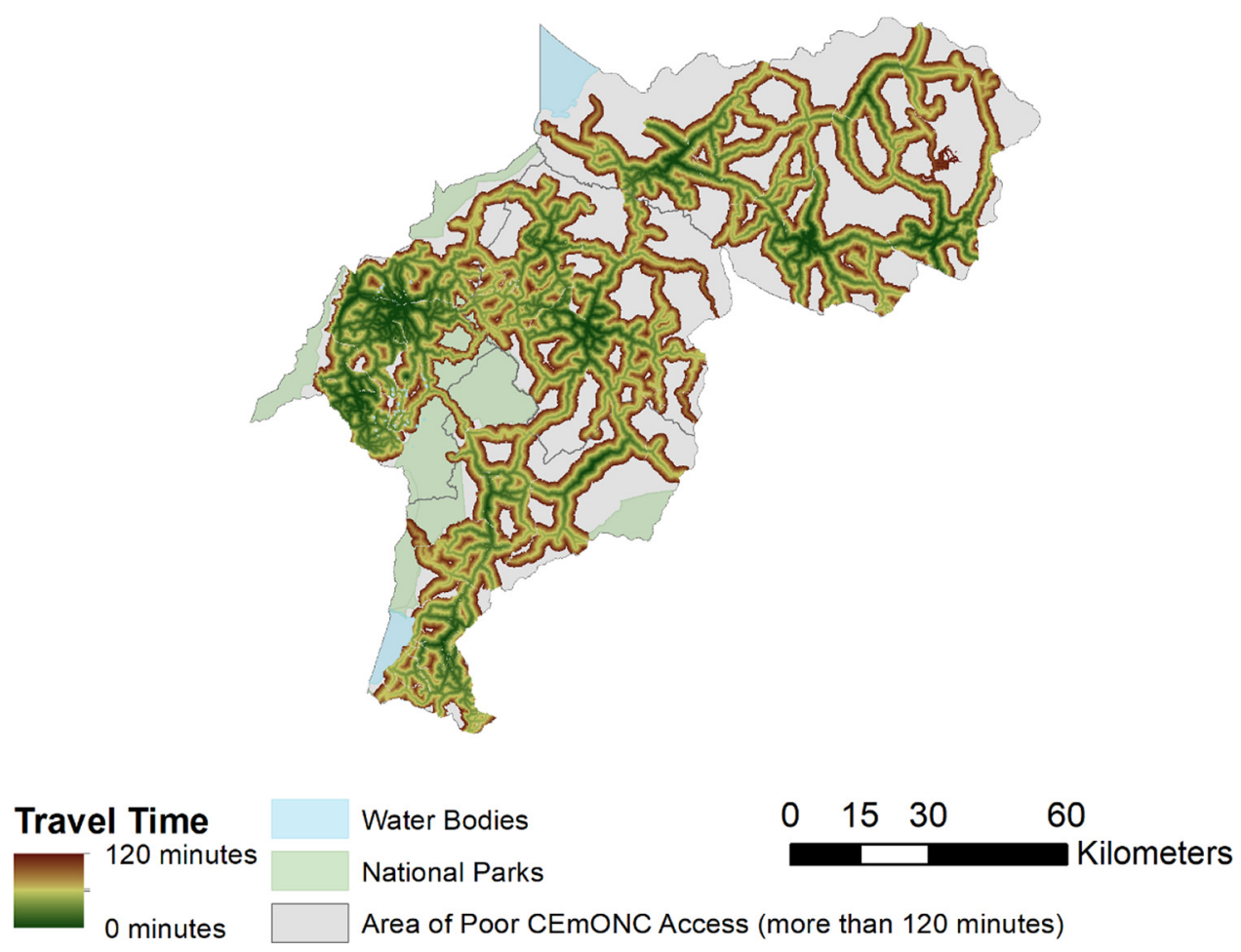

a Transportation defined as motorcycles or 4-wheeled vehicles.

Abbreviation: CEmONC, comprehensive emergency obstetric and newborn care. 
and placement of other essential services such as family planning and HIV testing.

Although SMGL did not capture systematic baseline and endline data on the actual transportation used by women in SMGL-supported districts to reach care, there is evidence that the actual use of motorized transport increased.

Geographic inaccessibility is a major barrier to reducing preventable maternal and newborn mortality and morbidity. Deliveries in EmONC facilities increased from $28.2 \%$ to $41.0 \%$ in the SMGL-supported districts in Uganda. ${ }^{19}$ According to exit interviews at EmONC facilities conducted at the conclusion of Phase 1, 90\% of women used motorized transportation to reach the EmONC where they delivered. ${ }^{53}$ Additionally, SMGL implementing partners supported the use of motorized transportation through "boda-formothers" vouchers-private-service vouchers that included subsidized motorcycle transportand organized a district ambulance network that included 5 4-by-4 ambulances and 16 eRanger tricycle ambulances at facilities. ${ }^{20,21}$ Linking ambulances through a district network allowed the closest ambulance to the emergency to be assigned for timely referral of mothers and newborn babies with complications. ${ }^{53}$ The redemption of vouchers increased over the SMGL implementation period, although the voucher supply was reduced in Phase 2 due to interruptions in funding. ${ }^{54}$ Although our geographic models included estimates of adequate access by walking, reaching delivery care by nonmotorized means is clearly not practical. Wider availability of motorized transportation to reach EmONC facilities is necessary to ensure adequate access.

Spatial analyses using GIS have great potential to inform programs and policies in safe motherhood initiatives. ${ }^{55}$ Our study was unique in that we were able to perform travel-time modeling across multiple time points of a multi-year safe motherhood project. The GIS analyses benefited from the project's investments in health systems strengthening at the district level and extensive monitoring and evaluation efforts.

Our travel-time models were based on the most recent data about road network, population, and facility functionality using health facility and reproductive health census data. While we had the opportunity to use direct current population counts by village instead of modeled raster population estimates, publicly available population raster data have been used in other travel-time modeling analyses. ${ }^{17,30,43,56-63}$

By using open-source programs-such as AccessMod-and advancements in geospatial technologies, it has become easier to perform meaningful actionable travel-time analyses that can be used with monitoring and evaluation programs. With minimum investment in measuring devices, training, and software, district personnel can use existing health information management data or special EmONC assessment studies in combination with population and land cover data to perform travel-time analyses.

\section{Limitations}

This analysis has several limitations. As noted, although we were able to estimate that an increased proportion of WRA had adequate access to EmONC at SMGL endline, the analysis was limited by the lack of data on actual changes in transportation use for women delivering in EmONC facilities. Therefore, we could not assess the relative contributions of decreased distance to care versus greater availability and use of motorized transportation. In addition, the actual proportion of WRA with adequate EmONC access may be lower or higher than our estimates due to assumptions we made. First, we used land and road class speeds that were relatively conservative compared with another recent global analysis. ${ }^{17}$ While lower than the average, the speeds we applied did not account for any variation that might have occurred due to varying road conditions/obstructions or traffic patterns. We estimated travel times for dry road conditions only and could not account for flooding or poor road conditions in rainy seasons. These types of barriers would most likely have reduced speed and lengthened travel time to care, or made travel impossible, as shown in a study conducted in Mozambique. ${ }^{64}$ We assumed that women walk in the most logical path-usually a straight line-from their homes to the nearest road, from where they would access the nearest facility. In real life, women may take various routes to access the nearest road and to travel to the nearest EmONC facility. They may take a longer route if a road or bridge is under repair or if they do not go to the nearest EmONC facility. They may temporarily move away from their home close to their delivery date to live in a family member's home or maternity waiting home near an EmONC facility. Our analysis also did not take into account referrals from lower-level facilities to EmONC facilities.

Additionally, our estimates did not differentiate between private and public facilities. Access times may be longer for WRA living within an 
adequate distance to private care but who have to travel further to a public facility. While SMGLsupported private service vouchers with transportation support could augment access to private delivery facilities among women who could otherwise not afford the costs, these vouchers were available only during Phase $1 .{ }^{20}$ Therefore, Phase 1 distance-to-care estimates may be less affected by differential access to private care than Phase 2 estimates.

\section{CONCLUSION}

Our study findings suggest that reducing distance to and increasing optimal distribution of EmONC facilities can increase adequate access to EmONC. Increases in the proportion of WRA with adequate EmONC access due to the SMGL initiative suggest that the SMGL-supported districts made significant advances in bridging the gap in access to timely emergency delivery care. Further gains could be achieved using spatial analyses to strategically estimate placement of EmONC services to reach the greatest number of geographically disadvantaged women, either through the addition of new facilities or upgrading of existing facilities already providing routine obstetric care.

Health care modeling of distance and travel time can help inform the planning of appropriate interventions to overcome spatial disparities in access to maternity care in sub-Saharan Africa. Geographic inaccessibility is a major barrier to countries' efforts to reduce preventable maternal and newborn mortality and morbidity. Periodic assessments of EmONC capabilities, locations, and travel time to EmONC services that take into account actual geographic conditions can enable policy makers and planners to make more informed decisions on the spatial distribution of services and the most effective strategies to improve access.

\begin{abstract}
Acknowledgments: We thank the country teams, partners, village health teams, and the residents of the SMGL-supported districts in Uganda. We thank Dr. Bernard Muhwezi, Mr. David Luswata, and Mr. Dennis Kimera of UBOS for providing relevant shapefiles. We additionally thank the USAID GeoCenter for its assistance with filling out the gaps in the road network via Humanitarian OpenStreetMap.
\end{abstract}

Funding: Saving Mothers, Giving Life implementation was primarily funded by the Office of the Global AIDS Coordinator, the U.S. Agency for International Development (USAID), Washington, D.C., the Centers for Disease Control and Prevention (CDC), Atlanta, Georgia (Cooperative agreements GPS003057 and GPS002918), Merck for Mothers, and Every Mother Counts. The funding agencies had no influence or control over the content of this article.
Disclaimer: The authors' views expressed in this publication do not necessarily reflect the views of the U.S. Government.

Competing Interests: None declared.

\section{REFERENCES}

1. Alkema L, Chou D, Hogan D, et al; United Nations Maternal Mortality Estimation Inter-Agency Group collaborators and technical advisory group. Global, regional, and national levels and trends in maternal mortality between 1990 and 2015, with scenario-based projections to 2030: a systematic analysis by the UN Maternal Mortality Estimation Inter-Agency Group. Lancet. 2016;387 (10017):462-474. CrossRef. Medline

2. Liu L, Oza S, Hogan D, et al. Global, regional, and national causes of under-5 mortality in 2000-15: an updated systematic analysis with implications for the Sustainable Development Goals. Lancet. 2016;388(10063):3027-3035. CrossRef. Medline

3. Lawn JE, Blencowe H, Waiswa $\mathrm{P}$, et al; Lancet Ending Preventable Stillbirths Series study group; Lancet Stillbirth Epidemiology investigator group. Stillbirths: rates, risk factors, and acceleration towards 2030. Lancet. 2016;387(10018):587-603. CrossRef. Medline

4. United Nations. The Millennium Development Goals Report 2015. New York: United Nations; 2015. http://www.un.org/en/ development/desa/publications/mdg-report-2015.html. Accessed January 16, 2019.

5. World Health Organization (WHO). Making Pregnancy Safer: The Importance of the Skilled Birth Attendant. A joint statement by WHO, ICM and FIGO. Geneva: WHO; 2004. http://www.who.int/ maternal_child_adolescent/documents/9241591692/en/. Accessed November 22, 2018.

6. World Health Organization (WHO). The World Health Report 2005 : Make Every Mother and Child Count. Geneva: WHO; 2005. http:// www.who.int/whr/2005/whr2005_en.pdf?ua=1. Accessed November 22, 2018.

7. Kyei-Nimakoh M, Carolan-Olah M, McCann TV. Access barriers to obstetric care at health facilities in sub-Saharan Africa-a systematic review. Syst Rev. 2017;6(1):1 10. CrossRef. Medline

8. Moyer CA, Mustafa A. Drivers and deterrents of facility delivery in subSaharan Africa: a systematic review. Reprod Health. 2013;10(1):40. CrossRef. Medline

9. Gabrysch S, Campbell OMR. Still too far to walk: literature review of the determinants of delivery service use. BMC Pregnancy Childbirth. 2009;9:34. CrossRef. Medline

10. Gabrysch S, Cousens S, Cox J, Campbell OMR. The influence of distance and level of care on delivery place in rural Zambia: a study of linked national data in a geographic information system. PLoS Med. $2011 ; 8(1)$ :e1000394. CrossRef. Medline

11. Kerber KJ, de Graft-Johnson JE, Bhutta ZA, Okong P, Starrs A, Lawn JE. Continuum of care for maternal, newborn, and child health: from slogan to service delivery. Lancet. 2007;370(9595):1358-1369. CrossRef. Medline

12. Holmer H, Oyerinde K, Meara JG, Gillies R, Liljestrand J, Hagander $L$. The global met need for emergency obstetric care: a systematic review. BJOG. 2015;122(2):183-189. CrossRef. Medline

13. Yakoob MY, Ali MA, Ali MU, et al. The effect of providing skilled birth attendance and emergency obstetric care in preventing stillbirths. BMC Public Health. 2011;11 (suppl 3):S7. CrossRef. Medline

14. Pirkle CM, Fournier P, Tourigny $C$, Sangaré K, Haddad S Emergency obstetrical complications in a rural African setting (Kayes, Mali): the link between travel time and in-hospital maternal mortality. Matern Child Health J. 2011 ; 15(7):1081-1087. CrossRef. Medline

15. World Health Organization (WHO); United Nations Population Fund (UNFPA); United Nations Children's Fund (UNICEF); Mailman 
School of Public Health. Monitoring Emergency Obstetric Care: A Handbook. Geneva: WHO; 2009. http://www.who.int/ reproductivehealth/publications/monitoring/9789241547734/ en/. Accessed November 22, 2018.

16. Meara JG, Leather AJM, Hagander L, et al. Global Surgery 2030: evidence and solutions for achieving health, welfare, and economic development. Lancet. 2015;386(9993):569-624. CrossRef. Medline

17. Ouma PO, Maina J, Thuranira PN, et al. Access to emergency hospital care provided by the public sector in sub-Saharan Africa in 2015: a geocoded inventory and spatial analysis. Lancet Glob Health. 2018;6(3):e342-e350. CrossRef. Medline

18. United Nations. Sustainable Development Goal 3. Sustainable Development Goals Knowledge Platform. https://sustainable development.un.org/sdg3. Accessed November 22, 2018.

19. Serbanescu F, Clark TA, Goodwin M, et al. Saving Mothers, Giving Life Working Group. Impact of the Saving Mothers, Giving Life approach on decreasing maternal and perinatal deaths in Uganda and Zambia. Glob Health Sci Pract. 2019;7(suppl 1):S27-S47. CrossRef

20. Serbanescu F, Goodwin MM, Binzen S, et al. Saving Mothers, Giving Life Working Group. Addressing the First Delay in Saving Mothers, Giving Life districts in Uganda and Zambia: approaches and results for increasing demand for facility delivery services. Glob Health $\mathrm{Sci}$ Pract. 2019;7(suppl 1):S48-S67. CrossRef

21. Ngoma T, Asiimwe AR, Mukasa J, et al. Saving Mothers, Giving Life Working Group. Addressing the Second Delay in Saving Mothers, Giving Life districts in Uganda and Zambia: reaching appropriate maternal care in a timely manner. Glob Health Sci Pract. 2019;7 (suppl 1):S68-S84. CrossRef

22. Morof D, Serbanescu F, Goodwin M, et al. Saving Mothers, Giving Life Working Group. Addressing the Third Delay in Saving Mothers, Giving Life districts in Uganda and Zambia: ensuring adequate and appropriate facility-based maternal and perinatal health care. Glob Health Sci Pract. 2019;7(suppl 1):S85-S103. CrossRef

23. Saving Mothers, Giving Life. Uganda. Saving Mothers, Giving Life website. http://savingmothersgivinglife.org/our-work/uganda. aspx. Accessed November 22, 2018.

24. Serbanescu F, Goldberg HI, Danel I, et al. Rapid reduction of maternal mortality in Uganda and Zambia through the Saving Mothers, Giving Life initiative: results of year 1 evaluation. BMC Pregnancy Childbirth. 2017;17:42. CrossRef. Medline

25. U.S. Centers for Disease Control and Prevention (CDC). Saving Mothers, Giving Life: Emergency Obstetric and Newborn Care Access and Availability, Phase 1 Monitoring and Evaluation Report. Atlanta, GA: CDC; 2014. https://www.cdc.gov/reproductivehealth/global/ publications/pdfs/smgl-emergencyobstetriccare-508.pdf. Accessed December 18, 2018.

26. Makanga PT, Schuurman N, von Dadelszen P, Firoz T. A scoping review of geographic information systems in maternal health. Int $J$ Gynaecol Obstet. 2016;134(1):13-17. CrossRef. Medline

27. Ebener S, Guerra-Arias M, Campbell J, et al. The geography of maternal and newborn health: the state of the art. Int $J$ Health Geogr. 2015;14(1):19. CrossRef. Medline

28. Chen YN, Schmitz MM, Serbanescu F, Dynes MM, Maro G, Krame MR. Geographic access modeling of emergency obstetric and neonatal care in Kigoma Region, Tanzania: transportation schemes and programmatic implications. Glob Health Sci Pract. 2017;5(3): 430-445. CrossRef. Medline

29. Saving Mothers, Giving Life. Nigeria - Accessibility to EmONC facilities in the State of Cross River. Washington, DC: USAID; 2016. https://pdf.usaid.gov/pdf_docs/pa00mdwb.pdf. Accessed December 18, 2018.
30. Gething PW, Johnson FA, Frempong-Ainguah F, et al. Geographical access to care at birth in Ghana: a barrier to safe motherhood. BMC Public Health. 2012;12:991. CrossRef. Medline

31. Salehi $F$, Ahmadian L. The application of geographic information systems (GIS) in identifying the priority areas for maternal care and services. BMC Health Serv Res. 2017;17:482. CrossRef. Medline

32. Sudhof $L$, Amoroso $C$, Barebwanuwe $P$, et al. Local use of geographic information systems to improve data utilisation and health services: mapping caesarean section coverage in rural Rwanda. Trop Med Int Heal. 2013;18:18-26. CrossRef

33. Regional Centre for Mapping of Resources for Development (RCMRD) Geoportal. 30-meter Resolution Land Cover Data Set for Uganda. Nairobi, Kenya: RCMRD; 2014. http://geoportal. remrd. org/layers/servir\%3Auganda_landcover_2014_scheme_i. Accessed December 18, 2018.

34. Uganda Bureau of Statistics (UBOS); ICF International. Uganda Demographic and Health Survey 2011. Kampala, Uganda and Calverton, Maryland: UBOS and ICF International; 2012. https:// dhsprogram.com/pubs/pdf/fr264/fr264.pdf. Accessed November 22, 2018.

35. Uganda Bureau of Statistics (UBOS). National Population and Housing Census 2014: Main Report. Kampala, Uganda: UBOS 2016. https://www.ubos.org/onlinefiles/uploads/ubos/NPHC/ NPHC\%202014\%20FINAL\%20RESULTS\%2OREPORT.pdf. Accessed November 22, 2018

36. Maine D. McCarthy J, Ward VM; United Nations Children's Fund (UNICEF) Statistics and Monitoring Division. Guidelines for Monitoring Progress in the Reduction of Maternal Mortality: A Work in Progress. New York: UNICEF; 1992.

37. Ministry of Health (MOH). Roadmap for Accelerating Reduction of Maternal and Neonatal Mortality and Morbidity in Uganda, 2007 2015. Kampala, Uganda: MOH; 2013. http://www. nationalplanningcycles.org/sites/default/files/country_docs/ Uganda/uganda_mnh_roadmap_2007-2015.pdf. Accessed November 22, 2018.

38. East Africa tagging guidelines. OpenStreetMap Wiki. http://wiki. openstreetmap.org/wiki/East_Africa_Tagging_Guidelines. Accessed December 2, 2018

39. Highway tag Africa. OpenStreetMap Wiki. http://wiki. openstreetmap.org/wiki/Highway_Tag_Africa. Accessed December 2, 2018.

40. United States Geological Survey (USGS). Shuttle Radar Topography Mission (SRTM) 1 arc-second global. USGS website. hitps://lta.cr. usgs.gov/SRTM1Arc. Accessed November 22, 2018.

41. United Nations Environment, International Union for Conservation of Nature. World database on protected areas. Protected Planet website. https://www. protectedplanet.net/c/world-database-onprotected-areas. Accessed November 22, 2018.

42. Uganda Bureau of Statistics (UBOS). National Population and Housing Census 2014: Provisional Results. Kampala, Uganda: UBOS; 2014. http://mww.ubos.org/onlinefiles/uploads/ubos/ NPHC/2014\%20National\%20Census\%20Main\%20Report.pdf. Accessed January 16, 2019.

43. Ray N, Ebener S. AccessMod 3.0: computing geographic coverage and accessibility to health care services using anisotropic movement of patients. Int J Health Geogr. 2008;7(1):63. CrossRef. Medline

44. First African Bicycle Information Organization (FABIO). http:// www.fabio.or.ug/. Accessed July 10, 2018.

45. eRanger. http://www.eranger.com/. Accessed July 10, 2018

46. Melbye DC, Møller-Jensen L, Andreasen MH, Kiduanga J, Busck AG. Accessibility, congestion and travel delays in Dar es Salaam - A time-distance perspective. Habitat Int. 2015;46:178-186. CrossRef 
47. Nelson AD. Travel time to major cities: a global map of accessibility. European Commission Joint Research Centre website. http://forobs. jrc.ec.europa.eu/products/gam/index.php. Accessed December $18,2018$.

48. World Health Organization (WHO). Violence and Injury Prevention: Country Profiles 2015. United Republic of Tanzania. Geneva: WHO; 2015. https://www.who.int/violence_injury_prevention/road_ safety_status/2015/country_profiles/United_Republic_of_ Tanzania.pdf?ua=1. Accessed December 18, 2018

49. Målqvist M, Sohel N, Do TT, Eriksson L, Persson LÅ. Distance decay in delivery care utilisation associated with neonatal mortality. A case referent study in northern Vietnam. BMC Public Health. 2010;10:762. CrossRef. Medline

50. Kosai H, Tamaki R, Saito $M$, et al. Incidence and risk factors of childhood pneumonia-like episodes in Biliran Island, Philippines $-a$ community-based study. PLoS One. 2015;10(5):e0125009. CrossRef. Medline

51. World Health Organization (WHO). Violence and Injury Prevention: Country Profiles 2015. Uganda. Geneva: WHO; 2015. https:// www.who.int/violence_injury_prevention/road_safety_status/ 2015/country_profiles/Uganda.pdf?ua=1. Accessed December 18, 2018.

52. Tobler W. Three Presentations on Geographical Analysis and Modeling. Non-Isotropic Modeling Speculations on the Geometry of Geography Global Spatial Analysis. National Center for Geographic Information and Analysis (NCGIA) technical report 93-1. Buffalo, NY: NCGIA; 1993. https://escholarship.org/uc/ item/05r820mz. Accessed January 16, 2019.

53. Sacks $E$, Vail $D$, Austin-Evelyn K, et al. Factors influencing modes of transport and travel time for obstetric care: a mixed methods study in Zambia and Uganda. Health Policy Plan. 2016;31(3):293-301. CrossRef. Medline

54. Saving Mothers, Giving Life. External Evaluation of Saving Mothers, Giving Life: Final Report. New York: Columbia University; 2013. http://savingmothersgivinglife.org/docs/SMGL-Columbia-finalreport-Oct-2013.pdf. Accessed January 16, 2019.
55. Molla YB, Rawlins B, Makanga PT, et al. Geographic information system for improving maternal and newborn health: recommendations for policy and programs. BMC Pregnancy Childbirth. 2017;17:26. CrossRef. Medline

56. Macharia PM, Odera PA, Snow RW, Noor AM. Spatial models for the rational allocation of routinely distributed bed nets to public health facilities in Western Kenya. Malar J. 2017;16:367. CrossRef. Medline

57. Tsoka JM, Le Sueur D. Using GIS to measure geographical accessibility to primary health care in rural South Africa: research in action. S Afr J Sci. 2004;100(7-8):329-330. hitps://journals.co.za/ content/sajsci/100/7-8/EJC96284. Accessed January 16, 2019.

58. Noor AM, Alegana VA, Gething PW, Snow RW. A spatial national health facility database for public health sector planning in Kenya in 2008. Int J Health Geogr. 2009;8:13. CrossRef. Medline

59. Alegana VA, Wright JA, Pentrina U, Noor AM, Snow RW, Atkinson PM. Spatial modelling of healthcare utilisation for treatment of fever in Namibia. Int J Health Geogr. 2012;1 1:6. CrossRef. Medline

60. Aoun N, Matsuda H, Sekiyama M. Geographical accessibility to healthcare and malnutrition in Rwanda. Soc Sci Med. 2015;130:135-145. CrossRef. Medline

61. Tatem AJ, Campbell J, Guerra-Arias M, de Bernis L, Moran A, Matthews Z. Mapping for maternal and newborn health: the distributions of women of childbearing age, pregnancies and births. Int $J$ Health Geogr. 2014;13:2. CrossRef. Medline

62. WorldPop project website. http://www.worldpop.org.uk. Accessed December 11, 2018.

63. Tatem AJ. WorldPop, open data for spatial demography. Sci Data. 2017;4:170004. CrossRef. Medline

64. Makanga PT, Schuurman N, Sacoor C, et al. Seasonal variation in geographical access to maternal health services in regions of southern Mozambique. Int J Health Geogr. 2017;16:1. CrossRef. Medline

\section{Peer Reviewed}

Received: September 22, 2018; Accepted: November 13, 2018

Cite this article as: Schmitz MM, Serbanescu F, Kamara V, Kraft JM, Cunningham M, Opio G, et al; Saving Mothers, Giving Life Working Group. Did Saving Mothers, Giving Life expand timely access to lifesaving care in Uganda? A spatial district-level analysis of travel time to emergency obstetric and newborn care. Glob Health Sci Pract. 2019;7(suppl 1):S151-S167. https://doi.org/10.9745/GHSP-D-18-00366

(c) Schmitz et al. This is an open-access article distributed under the terms of the Creative Commons Attribution 4.0 International License (CC BY 4.0), which permits unrestricted use, distribution, and reproduction in any medium, provided the original author and source are properly cited. To view a copy of the license, visit http://creativecommons.org/licenses/by/4.0/. When linking to this article, please use the following permanent link: https:// doi.org/10.9745/GHSP-D-18-00366 